\title{
Development of a Web-enhanced Senior Biomedical Engineering Design Course
}

\author{
Paul H. King, Ph.D., P.E. \\ Vanderbilt University
}

\section{Introduction:}

The senior year Biomedical Engineering experience at Vanderbilt University used to require two disassociated courses: BME 280 - Introduction to Biomedical Computing (Fall, 3 credits), and BME 272 - Design of Biomedical Engineering Devices and Systems (Spring, 3 credits). BME280 covered such topics as monitoring, image analysis, patient information systems, and database and statistical techniques. BME272 began with a series of lectures and exercises on the general process of design (modeled after a NSF /ASEE Creative and Structured Design Methods Workshop, 1989) accompanied by design project requests. After about 6 weeks the remainder of the term was dedicated to project development.

The Biomedical Computing course was difficult to administer and teach, as the student body came in with quite disparate backgrounds. Several students, especially those with BME-EE backgrounds, were well versed in some of the lecture material and did not like the class; others did not see the relevance of the course to their careers. The design course was reasonably well received, though a universal comment was that there was not enough time to properly complete many of the projects, as only about two and a half months were available to work on the projects. Several students suggested that the course become a full year offering in their year-end evaluations in order that more time could be devoted to completion of projects. Many students were concerned that the short time allotted would only allow prototype design, rather than construction.

The web presence of these two courses prior to this year was limited to course descriptions and a brief outline (272).

As a result of the above experiences, the department chose to combine the two courses in a new offering termed BME 272-273, Design of Biomedical Engineering Devices and Systems I and II [3-3]. The new course descriptions is: An integration of the engineering and life science backgrounds of senior biomedical engineering students through the presentation of design principles for medical devices and systems. 272: Design principles and case examples for biomedical electronics, mechanical, chemical, and computing systems. 273: A full semester design project is required. Evaluation via periodic oral and written presentations and a final written and poster report.

\section{Design Course Structure, First Semester:}

The Fall Semester offering of the course is primarily lecture oriented, with course communication outside of the classroom occurring through postings on a course web site. 
This web site was initially developed using Microsoft FrontPage97; it is maintained using FrontPage98. A listing of the primary sections of the web site may be found in table 1 . Of potential importance is the fact that the web page has both a course outline (section 8) and a listing of actual performance (section 9). Section 9 was used as the primary communication tool for the course, links were developed from this section to posted homework assignments, reading materials, lecturer materials, student project descriptions (proposed and taken), and relevant outside sites.

A listing of the Fall semester grade structure may be found in table 2. Material and exercises that had been previously covered in prior design lectures continued with assignments 2 (Capnometry project), 3 (flowcharting exercise), 4 (structured design exercises), and 12 (safety lectures feedback.) Tools that had been previously touched upon in the Biomedical Computing course, such as web page design, Visual Basic, $\mathrm{C}++$, Java, and InterDev, along with examples and exercises in Microsoft Access are integrated with discussions of past and present design projects of faculty and students. Additionally these subjects were graded in the performance of assignments 1 (Access based survey of student skills), 6 (development of one of 4 Access Database Assignments), and 10 (development of the groups' design project web site.). An optional Visual Basic homework assignment offers a chance to make up for any numerical deficiencies in the above or other areas.

Of major importance is an industry sponsored re-engineering project (assignment 8). This years' project involved the re-engineering of two devices - one of which was out of patent protection and soon to be no longer manufactured, the other was to be no longer manufactured. Team leaders were chosen from the subset of the class that are joint Biomedical Engineering and Electrical Engineering double majors. The class was then broken up into ten teams of 6 students each under their direction. Each group was charged with studying the current designs and proposing a redesign of the elements into a single new device. Students presented both oral and written reports on this exercise. The project was additionally offered as a term project. This portion of the course will be continued in the future, given industrial sponsorship. It offers a unique view of industrial needs to students who have mainly experienced the academic engineering and academic medical aspects of the department.

Once these tools and basic design methodology are introduced, students spend the remainder of the fall term on a final student design project. These projects are generally those posted on the web site, some of which have been orally presented to the class. One or two groups per year self-select a project. Project groups are generally kept to one or two members, except in rare cases where the instructor and project proposer agree on a larger number. Grades are earned for the formal written project proposal (9), development of the project web site (10), and weekly progress reports (11). The current 36 projects may be categorized as: hardware oriented (15), software-oriented (12), and a mixture of the two (9). Five projects involve Access databases, at least four utilize Visual Basic, one Java, and one Visual Studio. 
Finally, a comprehensive exam is used to determine attendance and interest in the lecture materials presented in class (5).

A review of the current web pages for the course may be made by visiting: http://www.bme.vanderbilt.edu/King/bme272.htm. Students have access to each other's web page sites, a friendly competition has arisen as a result. (See: http://www.bme.vanderbilt.edu/King/1997_1998Projects.htm ).

\section{Design Course Structure, Second Semester:}

The second semester of this course is devoted exclusively to work on the student design projects. Evaluation (see table 3 ) is via periodic oral presentations in front of the instructor and advisor (invited), weekly written progress reports (alternate weeks), generation and maintenance of project web pages, and a final poster presentation and written report for the project. The periodic oral report is of value in maintaining continuity of student effort during the term. A review of the current web pages for this course may be made by visiting: http://www.bme.vanderbilt.edu/King/bme273.htm.

\section{Web Enhancing means?}

One should be asking by this time just what then is meant by the title of this paper: Development of a Web-enhanced Senior Biomedical Engineering Design Course, and how is this different than other classical variations on the theme of design instruction? What are the advantages and disadvantages of this method and what lessons can be learned?

\section{Web enhancement involves electronic posting of course materials by the instructor.}

It is this author's opinion that the use of the web for distribution of course material for such a class is of value to the students. For a class such as this, with 60 students being presented with topics from some 30 potential advisors offering some 70 different projects - electronic posting of the topics and contacts is far preferable to paper notes posted on a corkboard or handed out to the class. The flexibility and immediacy of this method of posting notices cannot be surpassed. Homework assignments further will never be lost using such a method; paper handouts seem to have a short half-life!

Posting of lecture outlines, lecture sources, web site explanations of various topics, and information of general use to the class gives continuity to the course, and a central repository of data for study in preparation for exams.

Web enhancing stops short of ALN (Asynchronous Learning Networks) techniques in that formal class meetings are used to present material to the students at scheduled class times. In like fashion, web enhancement is not distance education, as physical attendance during part of the semester is necessary. 


\section{students.}

Web enhancement involves electronic posting of course results by the

All students in this course have access - on campus - to email and web site services (space on server, email clients, addresses, etc.) The Engineering School has purchased a site license for Microsoft Office 97, a separate grant from Microsoft for this course gave students access to Visual Basic, Visual C++, Visual Java, and Visual InterDev.

A mandatory portion of the course grade in this course comes from the student learning how to present project progress notes and results from their work on the web. While this is currently taught to incoming freshmen, this service was not available to upperclassmen when they were new. Combined electronic and oral presentations (Microsoft PowerPoint, for example) also was not easily available three years ago, use of PowerPoint is stressed in this course.

\section{Web enhancement is useful.}

Use of the web for posting of student projects and progress reports allows communication unparalleled in the past. Each student, and the instructor, can keep posted on the work and results of all the project groups. This data (when archived) may serve the students well later in their search for employment, and the department in review for accreditation. The use of the web for posting of frequently asked questions is very saving of instructor time.

\section{Lessons learned:}

The author had experience in several facets of static web page development prior to converting this course heavily to a web-enhanced course. It was surprising how fast short web pages became multiple web pages; a rework of the way information is structured is a continuous effort. A complete redesign, and the implementation of an NT based web server, is anticipated shortly. Overall, the strategy of using the web for information dissemination has proven extremely useful in this design course sequence. Increased student enthusiasm is evident as a result of this restructuring.

\section{Plans:}

We will continue to use the web in these courses, as it has proven to be of value as a communication tool. A chat section will be added to help elaborate on student and instructor expectations, a calendar section will be added to assist students in meeting the instructors' deadlines. We further plan to add formal exercises in applications such as use of the web to enable database input and data access. The use of the web for presentation of real-time (patient or process) information will additionally be developed. The use of the web for other real-time information transfer, such as video and audio information, will also be implemented. 
Supported in part by a Microsoft Academic Cooperative Grant Number 97807. Thanks to Dee Adams, student last year, TA this year in the course, for his critical input. Thanks to Andy Bass, student several years ago, webmaster today. Thanks to Paul Clayton, student this year, for his input on web page redesign.

PAUL H. KING, Ph.D., P.E. is an Associate Professor of Biomedical Engineering, Mechanical Engineering, and Anesthesiology at Vanderbilt University, Nashville TN 37235. Development of the original and the enhanced senior design course has been his responsibility.

\section{Table 1: Web Page Structure}

1. Course Description

2. Instructor and TA

3. Places and Facilities

4. Course Objective

5. Course Outline/Structure

6. Textbook

7. Grading Structure

8. Topical Outline

9. Actual Performance \& Assignments 1997-1998

10. Projects 1997-1998

11. Student Project Listing 1997-1998

12. Past Projects (1997 Spring)

13. Honor Code Statement

14. Please read: Fire \& Misc. Information

15. Kudos

16. Personal Statement 


\section{Table 2: Fall Semester Grading Structure}
Item number
Assignment
Assignment Value (\%)

\begin{tabular}{|c|l|c|}
\hline 1 & class survey & 1 \\
\hline 2 & CO2 homework & 1 \\
\hline 3 & JellyBelly Plant tour/itemization & 1 \\
\hline 4 & NSF assignments 1,2,3 & 3 \\
\hline 5 & Midterm Exam & 30 \\
\hline 6 & Database Term Assignment & 10 \\
\hline 7 & Design Project Topic, etc. by 11/6/97 & 1 \\
\hline 8 & 4 Week design project (Re-engineering) & 25 \\
\hline 9 & Formal Project Proposal (complete) & 10 \\
\hline 10 & Project Web Presence & 5 \\
\hline 11 & Progress Reports (email \&/or web) & 10 \\
\hline 12 & Safety assignment & 3 \\
\hline & & 100 \\
\hline
\end{tabular}

\section{Table 3: Grading Scheme - Spring}

Item Number Item Description
\begin{tabular}{|c|l|c|}
\hline 1 & Oral/PowerPoint Presentations bi or tri weekly & Total Point Value \\
\hline 2 & Weekly reports the other weeks & 10 \\
\hline 3 & Complete web presentation & 10 \\
\hline 4 & Poster session judge 1 & 10 \\
\hline 5 & Poster session judge 2 & 10 \\
\hline 6 & Advisor grade (poster, report, performance, etc.) & 10 \\
\hline 7 & Instructor grade (report, overall) & 30 \\
\hline & & $\underline{20}$ \\
\hline
\end{tabular}

